\title{
ECONOMIC IMPACTS OF GLOBAL WARMING: THE CASE OF THE BARENTS SEA FISHERIES
}

\author{
ARNE EIDE \\ The Norwegian College of Fishery Science \\ University of Troms $\varnothing$, Norway \\ E-mail: arne@nfh.uit.no
}

\begin{abstract}
Regional analyses of possible physical and biological effects of global warming in the Barents Sea area have been carried out recently. Based on such studies possible economic impacts of global warming on the Barents Sea fisheries have been quantified, assuming different types of management regimes. The EconSimp2000 model, consisting of the ecosystem model AggMult and the fleet model EconMult have been parameterized based on fleet and catch records from the Norwegian Barents Sea fisheries. The model has been used to study biological and economic impacts of different environmental scenarios representing possible consequences of global warming. The current environmental situation, including normal seasonal and other variations, has been used as a reference scenario. Several biological and economic indicators have been defined in order to evaluate the simulation results of different environmental scenarios and different types of management regimes. The findings support earlier studies where biological and economic impacts of changes in management regime is found to be more pronounced than impacts caused by effects of global warming.
\end{abstract}

KEY WORDS: Global warming, fisheries, economic impact, EconMult.

1. Introduction. The fact that we are in a period of global warming is overwhelmingly documented by a vast number of scientific studies over the last ten years, see for example, (Houghton [2005]). A full understanding of the driving forces is however yet not achieved, even though this has been given a lot of attention. Recently more attention has been paid to studies of global warming impact on human life and vulnerability studies. Knowing that global warming actually is taking place, the important question is how this will affect society and how the physical constraints of human activities are changed.

This study is a part of the European $B A L A N C E$ project which aim is to assess vulnerabilities of climate changes in the Barents region. 
Within the $B A L A N C E$ project integrated vulnerability studies based on the IPCC SRES scenario B2, world region OECD90 are carried out. The B2 scenario assumes local solutions to economic, social and environmental sustainability issues and intermediate economic development (the regional/environmental scenario).

Regional analyses based on global climate model runs need higher resolution than what is available through global model data. The choice of proper downscaling methods therefore represents a major challenge. Downscaling to regional level (the Barents region) in the BALANCE project is done by the REMO5.1 model (Jacob et al. [2001]), giving input values of physical variables to the ocean circulation model SinMod (Pedersen et al. [2003]). SinMod also covers primary and secondary biological production in Atlantic and Arctic waters of the Barents Sea.

Preliminary SinMod results indicate that there will be an increase in average sea temperature in the 50 meter upper layer of the Atlantic water in the range of +2 to +3 Celsius degrees 30 years from now compared with today's temperature. This temperature lies within the range of -2 to +3 Celsius degrees, compared with the current level, as assumed in the study of the Barents Sea fisheries by Eide and Heen [2002].

Uncertainty regarding the future thermohaline circulation (THC) and the effect global warming will have on the THC has however not been targeted in the BALANCE project. The importance of THC for the temperature in the Barents Sea and the great uncertainty in predicting the future THC, see for example, Knutti and Stocker [2002], give reasons for applying a methodology including a larger temperature range. This study therefore considers the same range of possible ocean temperatures as in the previous study by Eide and Heen [2002]. This includes a possibility of a cooling in the Barents Sea in the case of global warming caused by a reduced flow of the Gulf Stream; assuming the effects of a weakened THC to override possible increase in southern winds and warmer atmospheric conditions in the Barents region (Vellinga and Wood [2002] and Rahmstorf [1997]). Without a reduced flow the preliminary results from the SinMod model indicate that a warming close to +3 Celsius degrees is most likely to happen in the Barents Sea area. 
The bioeceonomic model EconSimp2000 includes the ecosystem module AggMult (Tjelmeland and Bogstad [1998a]) and the fleet module EconMult (Eide and Flaaten [1998]). The AggMult model includes a temperature variable affecting biological growth and recruitment. Natural temperature variation (seasonal and annual, see Ottersen et al. [2000]) is simulated by stochastic representation of historical temperature observations. The two extremes of -2 and +3 Celsius degrees are added to the natural variation.

EconSimp2000 has year 2000 as base year of the fleet model parameters, which includes both economic parameters and catch technological parameters. The start year of simulations presented in this article is 2005, assuming economic and technological parameter values of 2000 to be valid in 2005 as for the following 30 years.

2. Ecosystem model (AggMult). A renewed AggMult model makes use of the same functionalities as the previous one documented by Tjelmeland and Bogstad [1998a]. It is consistent with the Multspec model (Bogstad et al. [1997] and Tjelmeland and Bogstad [1998b]), applying most of the core functions, but aggregates in space and adds early life dynamics to the model. The latter causes differences in the recruitment modeling, see Tjelmeland and Bogstad [1998a] for details.

AggMult covers a highly dynamic ecosystem where all the exploited species normally experience fluctuating environmental conditions from year to year and between seasons within each year. Variations in sea temperature between and within years reflect some of the fluctuations. Many studies link individual growth, recruitment and other biological functions to temperature. AggMult includes a temperature variable implementing this biological knowledge in the ecosystem model. Even though the built-in functions in most cases are straightforward and predictable, e.g., increased temperature will up to certain threshold levels increase individual growth rates, the overall effect of a large mix of such functions in a complex ecosystem may not be obvious.

In addition, a number of powerful buffering mechanisms, such as cod cannibalism (Wikan and Eide [2004]), respond to environmental changes, including changes in the biological environment. Changes in growth rates, maturation age and the age structure of a stock may lead to changes in predation pattern and complex lagged effects. The 
fishers also adapt to variations in the ecosystem, dynamically changing fishing pattern, which also affects the future ecosystem development. All these rather complex dynamics are essentially described as deterministic processes. The life span of the main species, all the feed back mechanisms, the fisheries dynamics and the many lagged effects, lead to a situation where no equilibrium (in this case limited multi-cycle equilibria) is obtained within a short period of 30 years.

The Barents Sea ecosystem is strongly dominated by the cod-capelin dynamics where also the spring spawning herring plays an important role. Since the herring primarily is a Norwegian Sea stock, it is not fully represented in AggMult, as this model only covers the Barents Sea area. Young herring (0-3 years old) flows occasionally, however, into the Barents Sea basin (Huse et al. [2002]), having a significant impact on the cod-capelin system. In AggMult the occurrence of herring inflow is one of several components representing the natural environmental fluctuations in the Barents Sea system, as described above. The three major components are:

- Mean temperature in the upper 50 meter layer of Atlantic water.

- The half value parameter $(H V P)$ in the Beverton-Holt recruitment function $(B H R)$ is assumed to reflect annual environmental conditions, for details see Tjelmeland and Bogstad [1998a]. In this study time series of $H V P$-estimates based on historical observations have been applied.

- The Beverton-Holt recruitment function:

$$
B H R=R_{\mathrm{MAX}} \frac{S S B}{H V P+S S B} .
$$

- Inflow of herring juveniles in the Barents Sea.

The two first components are synchronized, as they both connect to the same environmental conditions (essentially inflow of Atlantic water), while the third component (herring) also involves biological factors (even though inflow of Atlantic water also here probably plays a crucial role). In function (1), controlling the recruitment of cod and capelin, these biological factors are represented by the spawning biomass $(S S B)$ and a maximum recruitment parameter $\left(R_{M A X}\right)$. 
Herring recruitment dynamics are, however, not defined within the frame of AggMult. The variations in herring abundance over a period of 100 years are described by Thoresen and Østvedt [2000], also presenting the enormous fluctuations in the herring recruitment over the period 1904-1994. Since herring inflow into the Barents Sea area involves both herring recruitment and a number of environmental factors, this process is represented stochastically in AggMult, employing historical observations within certain restrictions (related to interrelations between years, as some environmental changes develop over several years). Several randomly selected seed random series have been studied, whereof one is presented in this article. Monte Carlo simulation involving a higher number of seed random series would be preferable but was not possible to carry out due to constraints on available computing power. The main conclusions from all the performed simulations were however identical to the ones presented in this article, where the randomly selected stochastic representation of herring inflow is identically repeated in all simulations while varying management regimes and environmental scenarios.

Inflow of young herring into the Barents Sea basin immediately affects the capelin stock, as capelin juveniles are preyed upon very heavily by herring (Hamre [1994], Tjelmeland and Bogstad [1998b]). This will again affect cod growth, as the loss of capelin from the cod perspective cannot be fully compensated by the increased herring stock. When entering the Barents Sea, young herring according to Hamre [1994] efficiently stop the energy transport from the ice shelf in the north east into the central Barents Sea area normally performed by the capelin stock. At the same time herring feeds and increases its total biomass until it leaves the Barents Sea, transporting its energy into the Norwegian Sea. Meanwhile the cod stock experiences less suitable food and increases predation on zooplankton, shrimp and probably cannibalism until the capelin stock recovers. The fluctuations generated by herring interact with fluctuations caused by changing environmental conditions (natural variations), lagged effects, changes in fishing pattern and others, in addition to changes in predation pattern caused by changes in age composition, prey biomasses and other causes interacting with the first. 
3. Fleet model (EconMult). Most of the basic functions are kept from the previous model as described by Eide and Flaaten [1998] (EconSimp2). Some minor changes have however been done, particularly in the cost equation and in some management routines.

The new cost equation splits variable costs into two categories by including two parameters: constant seasonal unit costs of effort (a vessel fishing day) and constant seasonal unit cost of harvest. The model parameters are mainly based on the Norwegian statistics published by Anonymous [2000], while the technological parameters are as described by Eide and Flaaten [1998].

The fleet model interacts with the ecosystem model through catches. EconMult regards catch as a discrete time process and calculates catch of each predefined biomass unit for each predefined fleet unit (vessel) by two variables: current biomass of each biomass unit and number of fishing days during each unit of time. Calculated catch values are brought back to the ecosystem model where the standing stock biomasses are recalculated.

The fleet at the simulation start year (2005) is the year 2000 Norwegian fleet. Russian catches are assumed to be performed by industrial trawlers with the same technological parameters as Norwegian trawlers. In all but one simulation the fleet changes dynamically throughout the simulation period of 30 years. The fleet changes are due to economic performance and predefined rates of entry to and exit from the fishery. As the age composition of stock and biomasses changes continuously and all stock-output elasticities are well below one, see Table 2, the most cost-efficient fleet group varies from period to period. A fixed optimized fleet structure is therefore not to be found, but the implemented fleet dynamics may contribute by improving the average fleet performance over time.

4. EconSimp2000 parameter values. As in the EconSimp2 model (Eide and Flaaten [1998]) EconSimp2000 has a time resolution of a quarter of a year. The parameterization of EconSimp2000 is based on annual surveys of the fishing fleet performed by the Norwegian Fisheries Directorate (Anonymous [2000]). Cost data are aggregated from the same source, distinguishing between three types of costs: fixed costs, variable costs related to catch and variable costs related 
to effort production. Eighteen fleet groups participate in the Barents Sea fisheries. ${ }^{1}$

The cod catch production equation of wet fish trawlers in the Barents Sea has been studied and estimated by Eide et al. [2003]. The catch has a significant seasonal profile which may be reflected by a seasonal fluctuation in catchability. The main season of the cod fisheries is in the spawning period during winter when the fish is more easily accessible. According to catch records from 17 trawlers over a period of 15 years (before the introduction of quota regulations), the seasonal profile may be expressed by the normalized catchability function

$$
q(s)=e^{k_{1}+k_{2} \sin \left(s \cdot k_{3}\right)+k_{4} \cos \left(s \cdot k_{5}\right)},
$$

$s$ being the normalized day number of a year $(s=0$ at day 1 and $s=1$ at day 365$)$. Five parameters are represented by $k ; k_{1}=-12.01, k_{2}=$ $-42.32, k_{3}=-0.12, k_{4}=2.408$ and $k_{5}=3.26$ (Eide et al. [2003]). Mean values of $q(s)$ within each quarter multiplied by 1000 are calculated to, respectively, 0.100084, 0.091778, 0.0508188 and 0.0556335 , starting in the beginning of the year. The same seasonal profile is assumed in all cod fisheries.

The seasonal profile caused by spawning and feeding migration of cod is reflected in the fleet activity, which also is influenced by other natural variations, quota regulations and other management means. In the cod fisheries modeled in EconSimp2000 the fleet activity over the year is represented by simple assumptions regarding utilizing the fleet capacity over the year: Number of fishing days are $100 \%$ of total number of working days in quarter 1 , the corresponding utilization in quarters $2-4$ are $50 \%, 20 \%$ and $30 \%$ respectively.

Calculation of catchability coefficients of the different fleet groups within each season is based on year 2000 catches and stock biomass estimates of each year class combined with gear specific selection properties of EconSimp2. Selection values of the gear groups represented in the cod fishery are presented in Table 1.

A scaling factor $(\sigma)$ of each vessel $(\nu)$ is calculated on an annual basis while assuming a Cobb-Douglas catch equation (3), using catch information from Anonymous [2000], the relative selection values of Table 1, the elasticities of Table 2 and the seasonal change in availability given by Equation (2).

$$
h(s, t, \nu)=q(s) \cdot \sigma_{\nu} \cdot n^{\alpha} x^{\beta}
$$


TABLE 1. Relative selection values $(\sigma)$ based on fleet groups 5, 10, 13, 24 and 21 in EconSimp2 (Eide and Flaaten [1998]).

Age groups of cod

\begin{tabular}{lccccccc} 
Gear & 3 & 4 & 5 & 6 & 7 & 8 & $9+$ \\
\hline Gill net & 0.000 & 0.000 & 0.085 & 0.248 & 0.297 & 0.255 & 0.115 \\
\hline Long line & 0.025 & 0.163 & 0.345 & 0.423 & 0.044 & 0.000 & 0.000 \\
\hline Danish seine & 0.015 & 0.066 & 0.145 & 0.355 & 0.233 & 0.120 & 0.066 \\
\hline Hand line & 0.027 & 0.175 & 0.356 & 0.400 & 0.045 & 0.000 & 0.000 \\
\hline Bottom trawl & 0.017 & 0.067 & 0.160 & 0.328 & 0.228 & 0.126 & 0.074 \\
\hline
\end{tabular}

TABLE 2. Catch elasticities of different fishing gears in the Barents Sea cod fishery, from EconSimp2 (Eide and Flaaten [1998]). Bold values are estimated, the others represent basic assumptions.

\begin{tabular}{lcc} 
Gear & $\begin{array}{c}\text { Effort/Output } \\
\text { elasticity } \\
(\alpha)\end{array}$ & $\begin{array}{c}\text { Stock/Output } \\
\text { elasticity } \\
(\beta)\end{array}$ \\
\hline Gill net & 1.000 & 0.730 \\
\hline Long line & 1.000 & 0.350 \\
\hline Danish seine & 1.000 & 0.440 \\
\hline Hand line & 1.000 & 0.500 \\
\hline Bottom traw $*$ & 1.232 & 0.424 \\
\hline Purse seine & 1.000 & 0.500 \\
\hline
\end{tabular}

*Estimates from Eide et al. (2003)

5. Management regimes. Six management regimes have been studied. The six management regimes are given codes and short descriptions in Table 3.

The list includes two levels of constant total allowable catch (TAC regimes), two regimes implementing precautionary approach (PA), limited entry (LE) and open access (OA). The standard PA management is used as reference management regime. In 2005 a new PA management regime was introduced in the Barents Sea cod fisheries, namely 
TABLE 3. Management regimes for the Barents Sea cod fisheries applied in the EconMult2000 simulations.

Fixed

\begin{tabular}{ccccl} 
No. & Code & Quota & fleet & Management regimes \\
\hline 1 & PA & yes & no & Precautionary approach (0 regime) \\
\hline 2 & 3PA & yes & no & Precautionary approach and the 3 year rule \\
\hline 3 & TAC1 & yes & no & $\begin{array}{l}\text { Constant catch quota equal 242.5 thousand } \\
\text { tonnes which is the actual Norwegian catch } \\
\end{array}$ \\
& & & quota of 2005. \\
\hline 4 & TAC2 & yes & no & $\begin{array}{l}\text { Constant catch quota equal } 400 \\
\text { thousand tonnes }\end{array}$ \\
\hline 5 & LE & no & yes & Limited entry. \\
\hline 6 & OA & no & no & Open access \\
\hline
\end{tabular}

the so-called 3 year rule PA management. This new regime adds a fuzzy logic looking management system (on the fuzzy logic control issue, see for example, Lewis and Liu [1996]) to the already established PA rules. The cod PA management follows these rules:

- The TAC value is calculated on the basis of the PA fishing mortality rate (currently 0.4).

- If the spawning biomass is estimated to be lower than the predefined precautionary approach level, currently 460,000 tonnes, the TAC value is reduced linearly down to 0 at the minimum spawning biomass level at which fishing is allowed (currently 220,000 tonnes).

The additional 3 year rules are:

- TAC is calculated as above for three consecutive years (based on stock prognosis), and the initial TAC value is set equal to the mean value of the three calculated TAC values. The prognostic model (PROST) makes use of a population dynamic model similar to what is assumed in virtual population analysis runs (VPA or XSA, see Åsnes [2005]).

- The TAC value is if necessary adjusted in order to avoid changes in $\mathrm{TAC}$ value which exceeds \pm 10 percent compared with the previous year. 
- If the spawning biomass is below the precautionary approach level, the $10 \%$ rule above does not apply, and the TAC value is reduced according to the first 3 year PA rule above.

A necessary additional rule for making long term simulations has been added in this study:

- The $10 \%$ rule is omitted if the previous year's spawning stock level was below the precautionary approach level and last year's TAC value was reduced according to this.

The new prognostic model for management purposes (PROST) has been linked to EconSimp2000 and is employed whenever PAmanagement regimes are included.

The Norwegian fleet size of limited entry management regime is calculated on the basis of the Norwegian TAC value of 2005, which was 242.5 thousand tonnes. This is obtained by utilizing $25 \%$ of the year 2000 fleet, which is sufficient to reach the catch quota of 2005. The limited entry regulation includes no additional constraints and the fleet structure is fixed during the simulation period.

In all management regimes except limited entry, fleet composition may change over the simulation period due to differences in profitability between different fleet segments; this also includes the open access situation. The entry/exit dynamics of each vessel group are set to annual changes of $5 \%$ and $3 \%$ respectively, controlled by annual wage paying ability within each group. Negative values lead to decrease in numbers of vessels within the vessel group, while positive values result in a corresponding increase. There are no predefined constrains on fleet size upward or downward, except for the obvious nonacceptance of negative vessel numbers.

Constant quota regulation regimes are represented by two different constant quota values, the 2005 level (242.5 thousand tonnes) and 400,000 tonnes, the latter being closer related to previously calculated maximum sustainable yield values.

Harvest activity is in all simulations assumed to be zero when contribution margins turn negative, and each vessel will only choose to fish when harvest revenue covers at least the running cost of the fishing activity. 
6. Environmental scenarios. In this article the temperature shift caused by global warming is assumed to occur immediately, systematically exaggerating the impact of global warming in order to ensure coverage of the whole range of possibilities. This defines three environmental scenarios: colder, warmer and no change (the zero scenario, only considering current natural variation).

It needs however to be pointed out that global warming may potentially have more dramatic impacts on the Barents Sea fisheries given that the environmental changes trigger significant shifts in the ecosystem structure. In this article the current ecosystem structure is assumed to remain, even though it may be significantly altered while keeping the same main species. The chosen scenarios (colder, warmer and no change) are identical to the scenarios of the earlier study by Eide and Heen [2002], which was a part of the European BASIS program (Lange [2003]), applying a less integrated model.

As pointed out by Eide and Heen [2002], global warming does not necessarily lead to warmer conditions in the Barents Sea. Even though preliminary results from the SinMod model indicate a warmer climate also in the Barents Sea, uncertainties regarding the Gulf Stream allows the possibility of a colder Barents Sea (Rahmstorf [1997]). Therefore, in this article the following three environmental scenarios are included:

0 . Current climactic situation (zero scenario),

1. Temperature shift by +3 degrees Celsius (warmer scenario),

2. Temperature shift by -2 degrees Celsius (colder scenario).

According to the SinMod runs referred to in the introduction, scenario 1 is most likely to happen, given that the Gulf Stream preserves its present state, while scenario 2 assumes a significant reduction in the present flow of the Gulf Stream. Scenario 0 is the reference scenario.

7. Results. Eighteen simulations over 30 years (2005-2034), covering three environmental scenarios (colder, current and warmer) and six management regimes (Table 3), were carried out, all including identical seed random processes stochastically representing herring presence in the Barents Sea area. The results are presented graphically in Figures 1,2 and 3. Figure 1 shows the biomass development throughout the period, Figure 2 the corresponding catch development 
Colder
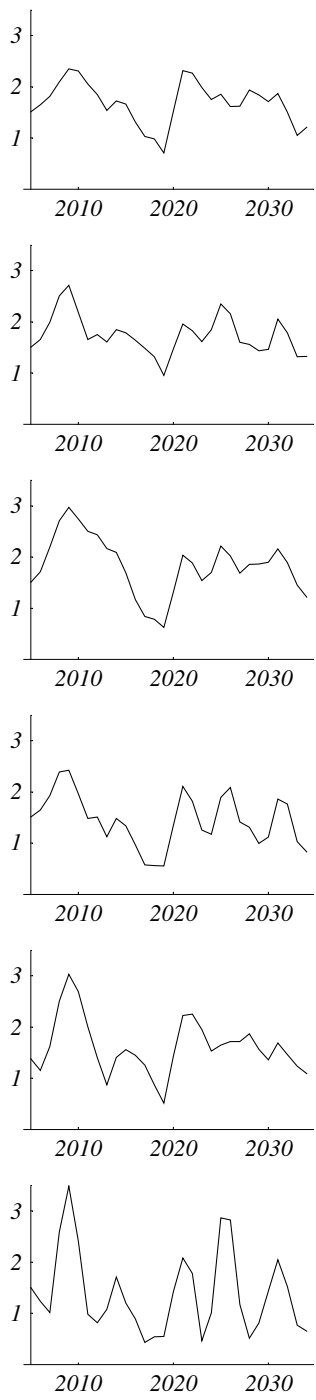

Current
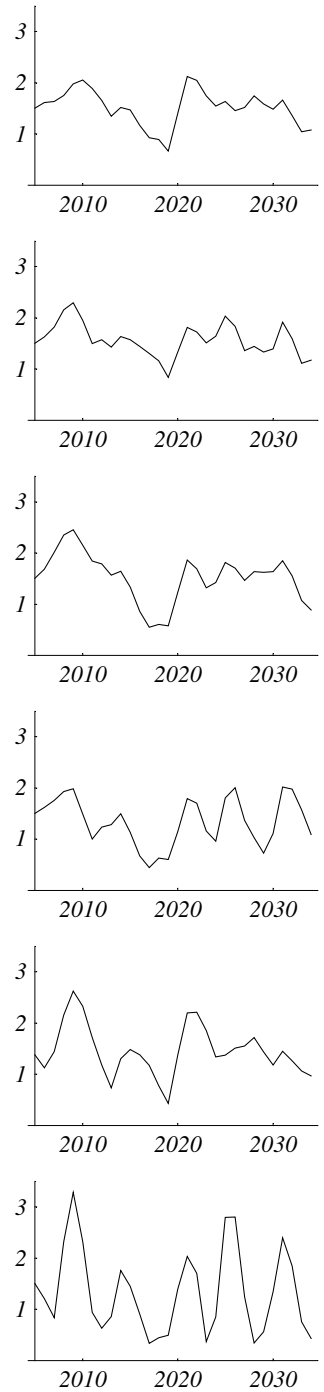

Warmer

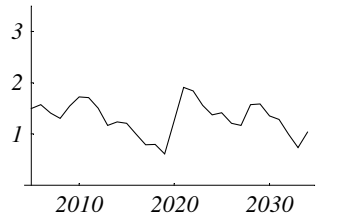

PA

$\mathrm{F}=0.4$

3PA

$\mathrm{F}=0.4$

3 year

$\mathrm{TAC}=$

242.5

$2010 \quad 2020 \quad 2030$

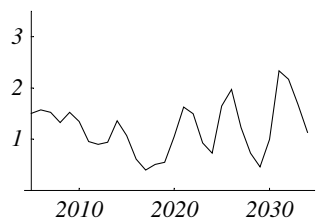

$\mathrm{TAC}=$

400

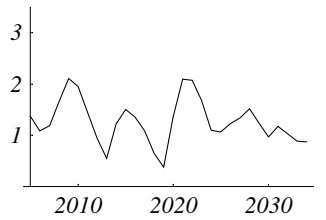

Limited

Entry

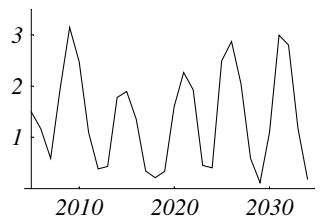

Open

Access

FIGURE 1. Cod stock biomasses in million tonnes during the simulation period 2005-2034 under different environmental conditions and management regimes. "Colder" climactic regime refers to a temperature change of $-2^{\circ} \mathrm{C}$ while "Warmer" refers to a temperature change of $3^{\circ} \mathrm{C}$ related to "Current" situation. The different management regimes are defined in Table 3. 
Colder
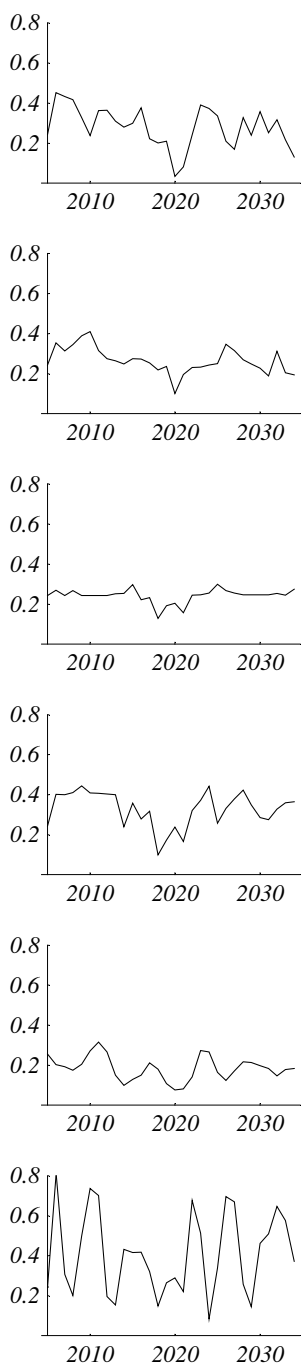

Current
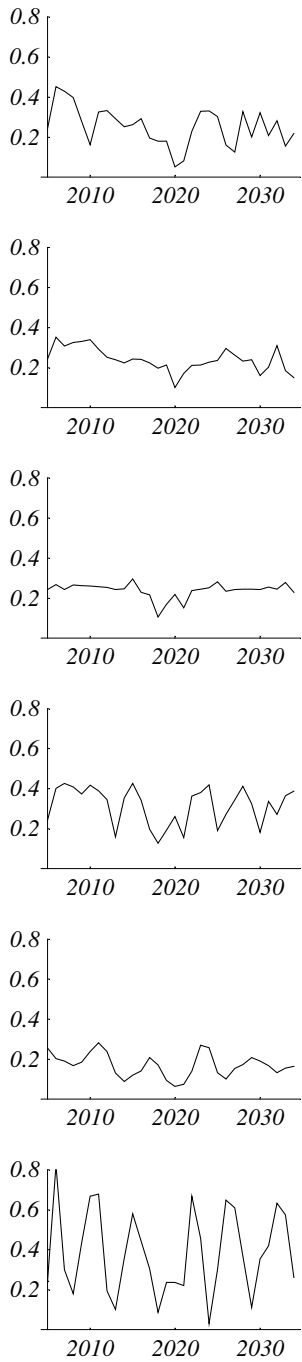

Warmer
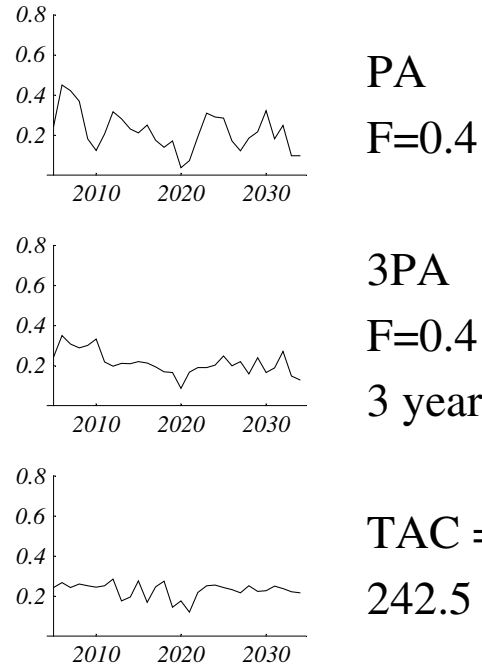

$\mathrm{TAC}=$ 242.5

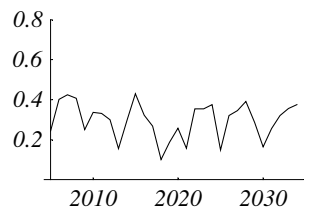

$\mathrm{TAC}=$ 400

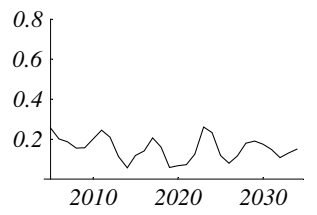

Limited

Entry

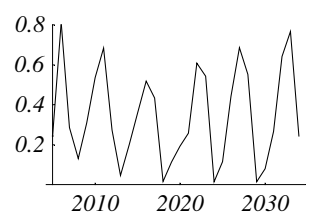

\section{Open}

Access

FIGURE 2. Cod catches in million tonnes during the simulation period 2005-2034 under different environmental conditions and management regimes. "Colder" climactic regime refers to a temperature change of $-2^{\circ} \mathrm{C}$ while "Warmer" refers to a temperature change of $3^{\circ} \mathrm{C}$ related to "Current" situation. The different management regimes are defined in Table 3. 
Colder
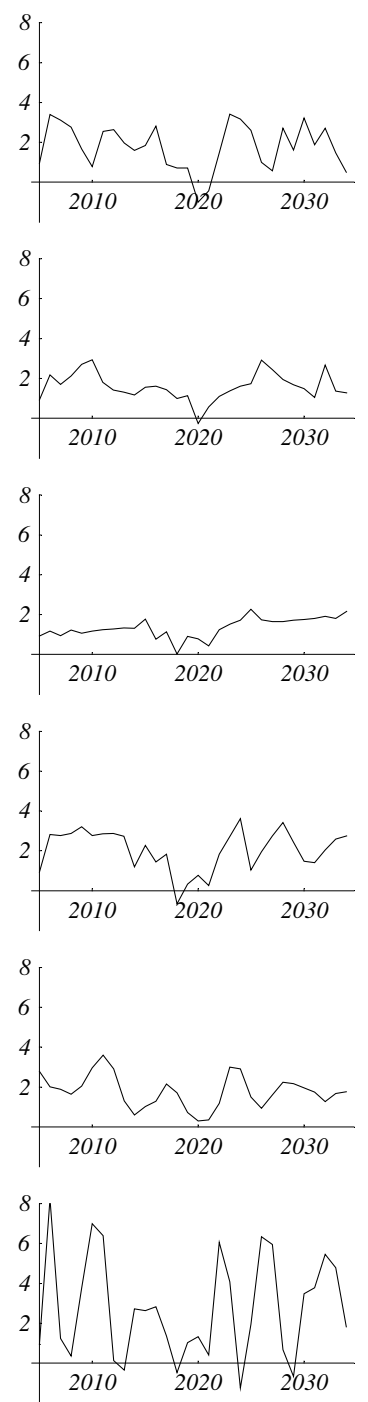

Current
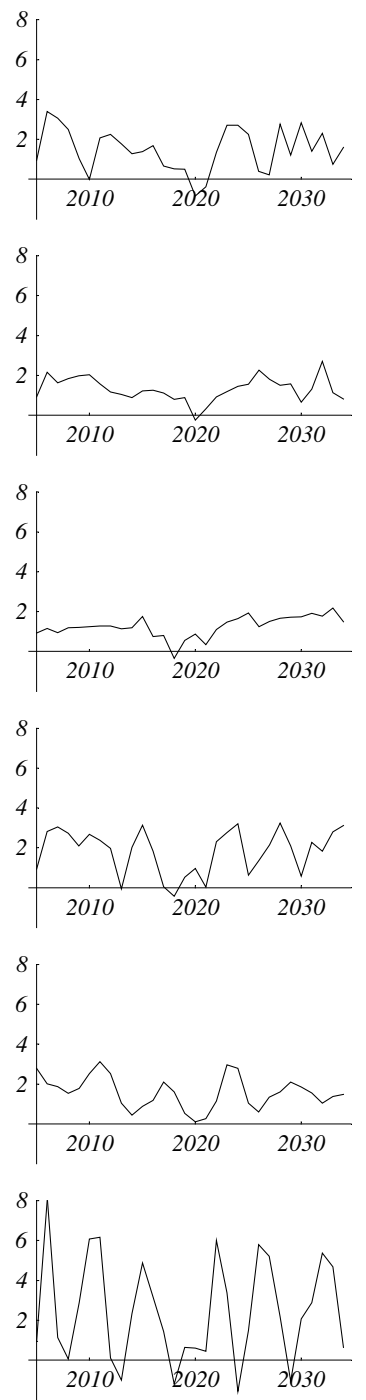

Warmer

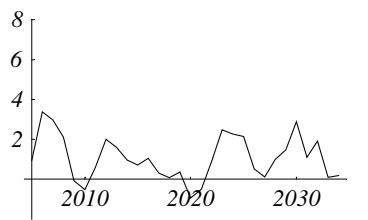

PA

$\mathrm{F}=0.4$

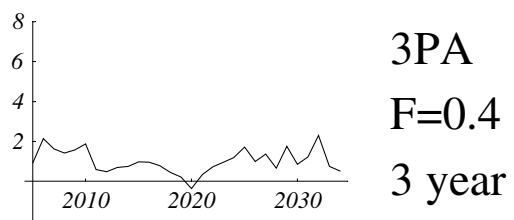

$\mathrm{TAC}=$

242.5

$\mathrm{TAC}=$

400

\section{Limited}

Entry

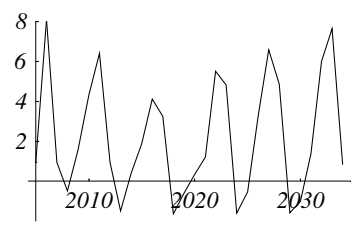

Open

Access

FIGURE 3. Annual total profit of the cod fisheries, in billion NOK, during the simulation period 2005-2034 under different environmental conditions and management regimes. "Colder" climactic regime refers to a temperature change of $-2^{\circ} \mathrm{C}$ while "Warmer" refers to a temperature change of $3^{\circ} \mathrm{C}$ related to "Current" situation. The different management regimes are defined in Table 3. 


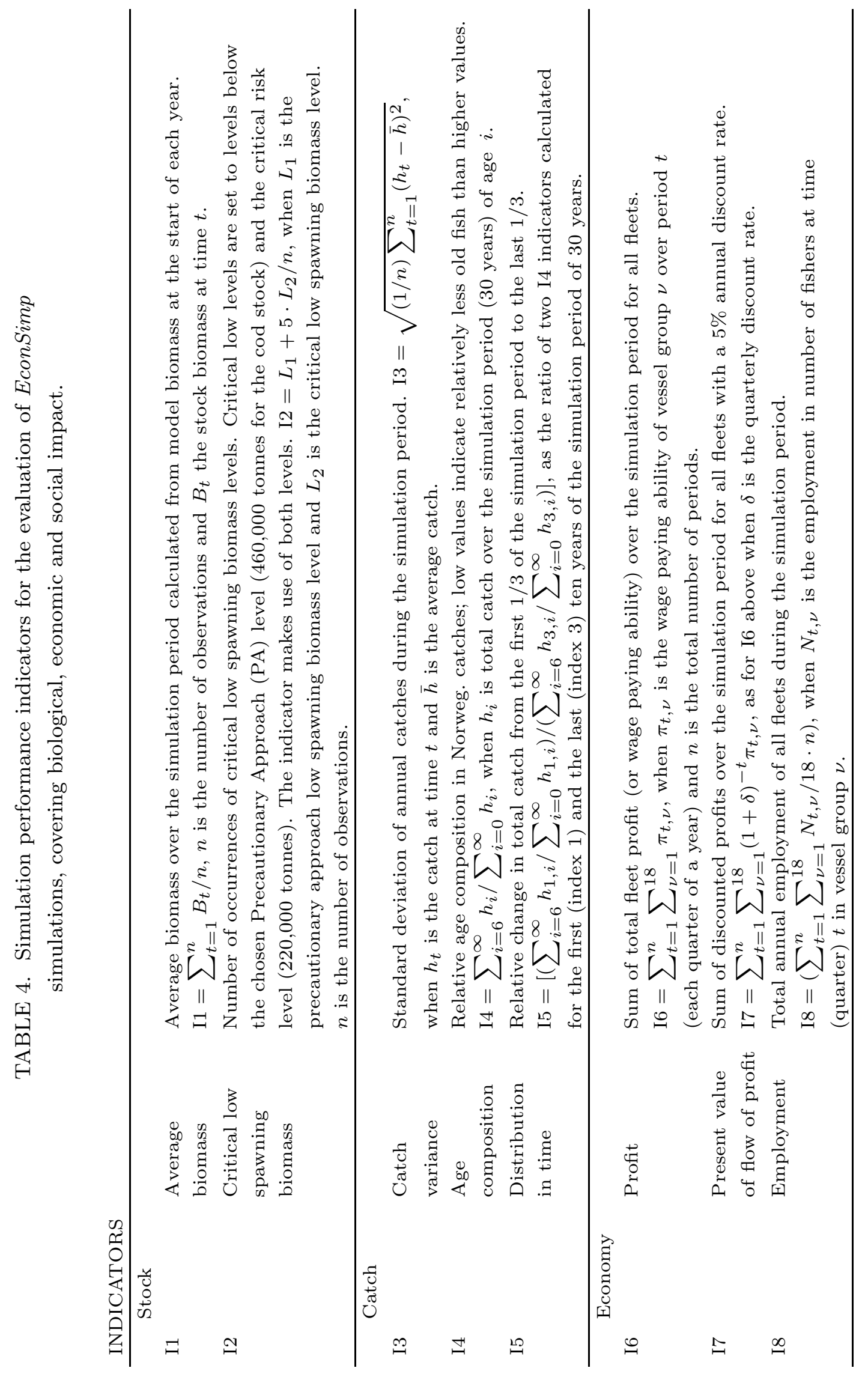


and Figure 3 the total profit (in this case the wage paying ability) development. The two latter are measured by annual values.

The results show highly fluctuating patterns over time in all the simulations with respect of biomass, catch and economic performance. The fluctuating patterns are not only related to the stochastic process mentioned above but more so to the representation of normal environmental variation implemented by time series of average temperatures and recruitment half values ( $H V P$, see equation (1)) and the complex dynamics through buffering mechanisms, feeding patterns and the lagged effects or earlier events.

The indicator values are presented in Table 5 normalized with respect of the PA management run in the zero scenario (current climate condition). In particular, the table displays information on differences between different management regimes and environmental scenarios. Profitability seems to be highly related to stock fluctuations (reflected by catch variances, but also in Figures 1-3), while stock indicators as frequency of low spawning stock situation, negative trends over time regarding age composition and catch distribution, are reduced by the same. The three management regimes causing the highest catch fluctuations are TAC2, LE and OA, which also represent the highest exploitation rates investigated. As expected, the open access regimes (OA) show the most critical stock indicators of all scenarios: While the critical low spawning biomass values seem to be reduced by increased temperature in the case of open access and limited entry (LE), constant catch quotas (TAC1 and TAC2) do not show a similar pattern.

8. Analysis. Eight indicators have been defined (Table 4) in order to analyze the simulation results presented above. The indicators cover the stock situation, catch properties and economic performance in the different simulation runs.

Cluster analysis has been performed on the indicators in order to study the relative importance of climactic changes (represented by the three scenarios) and different management regimes. The cluster analysis is presented in Table 6 and Figure 4.

Table 6 indicates a close relationship between management regimes representing high exploitation rates (OA and $\mathrm{TAC} 2$, partly $\mathrm{LE})$ and a 
TABLE 5. Indicator values of the 18 performed simulations, covering the period 2005-2034. All indicators are related to the PA management simulation of the current climactic conditions (bordered) and are measured by relative deviation.

Colder climactic conditions $\left(-2^{\circ} \mathrm{C}\right)$ :

\begin{tabular}{|c|c|c|c|c|c|c|c|}
\hline & & TAC1 & $3 \mathrm{PA}$ & $\mathrm{PA}$ & $\mathrm{LE}$ & TAC2 & OA \\
\hline \multirow[t]{3}{*}{ Stock } & Average biomass & 1.05 & 1.12 & 1.11 & 0.92 & 0.85 & 0.84 \\
\hline & Critical low & 1.67 & 0.00 & 1.00 & 5.50 & 5.33 & 6.17 \\
\hline & spawning biomass & & & & & & \\
\hline \multirow[t]{3}{*}{ Catch } & Catch variance & 0.64 & 0.93 & 1.05 & 1.36 & 1.23 & 2.32 \\
\hline & Age composition & 0.90 & 0.99 & 1.00 & 0.84 & 0.65 & 0.47 \\
\hline & Distribution in time & 0.97 & 0.69 & 0.95 & 0.75 & 0.27 & 0.42 \\
\hline \multirow[t]{3}{*}{ Economy } & Profit & 0.85 & 0.81 & 0.83 & 1.13 & 1.37 & 1.36 \\
\hline & $\begin{array}{l}\text { Present value of } \\
\text { flow of profit }\end{array}$ & 0.72 & 0.78 & 0.81 & 1.12 & 1.33 & 1.42 \\
\hline & Employment & 1.07 & 1.01 & 1.00 & 0.53 & 1.32 & 1.42 \\
\hline \multicolumn{8}{|c|}{ Current climactic conditions: } \\
\hline & & TAC1 & $3 \mathrm{PA}$ & $\mathrm{PA}$ & $\mathrm{LE}$ & TAC2 & OA \\
\hline \multirow[t]{2}{*}{ Stock } & Average biomass & 0.85 & 1.00 & 1.00 & 0.83 & 0.79 & 0.80 \\
\hline & $\begin{array}{l}\text { Critical low } \\
\text { spawning biomass }\end{array}$ & 3.83 & 1.00 & 1.00 & 6.50 & 6.50 & 8.00 \\
\hline \multirow[t]{3}{*}{ Catch } & Catch variance & 0.60 & 0.95 & 1.00 & 1.45 & 1.40 & 2.48 \\
\hline & Age composition & 0.80 & 0.98 & 1.00 & 0.83 & 0.65 & 0.48 \\
\hline & Distribution in time & 0.52 & 0.62 & 1.00 & 0.64 & 0.43 & 0.48 \\
\hline \multirow[t]{3}{*}{ Economy } & Profit & 0.79 & 0.64 & 1.00 & 1.00 & 1.22 & 1.23 \\
\hline & $\begin{array}{l}\text { Present value of } \\
\text { flow of profit }\end{array}$ & 0.69 & 0.63 & 1.00 & 1.01 & 1.19 & 1.31 \\
\hline & Employment & 1.10 & 1.01 & 1.00 & 0.53 & 1.43 & 1.42 \\
\hline \multicolumn{8}{|c|}{ Warmer climactic conditions $\left(+3^{\circ} \mathrm{C}\right)$ : } \\
\hline \multirow{4}{*}{ Stock } & & TAC1 & $3 \mathrm{PA}$ & $\mathrm{PA}$ & $\mathrm{LE}$ & TAC2 & $\mathrm{OA}$ \\
\hline & Average biomass & 0.71 & 0.83 & 0.84 & 0.73 & 0.66 & 0.79 \\
\hline & Critical low & 7.83 & 0.00 & 0.00 & 6.00 & 12.33 & 7.83 \\
\hline & spawning biomass & & & & & & \\
\hline \multirow[t]{3}{*}{ Catch } & Catch variance & 0.77 & 1.17 & 1.21 & 1.59 & 1.20 & 2.88 \\
\hline & Age composition & 0.77 & 0.98 & 0.99 & 0.85 & 0.59 & 0.51 \\
\hline & Distribution in time & 0.53 & 0.59 & 1.07 & 0.56 & 0.44 & 0.57 \\
\hline \multirow[t]{3}{*}{ Economy } & Profit & 0.70 & 0.40 & 0.43 & 0.87 & 1.17 & 1.09 \\
\hline & $\begin{array}{l}\text { Present value of } \\
\text { flow of profit }\end{array}$ & 0.61 & 0.42 & 0.46 & 0.90 & 1.10 & 1.12 \\
\hline & Employment & 1.10 & 1.01 & 1.00 & 0.53 & 1.44 & 1.42 \\
\hline
\end{tabular}




\section{Canberra Distance Dendrogram}

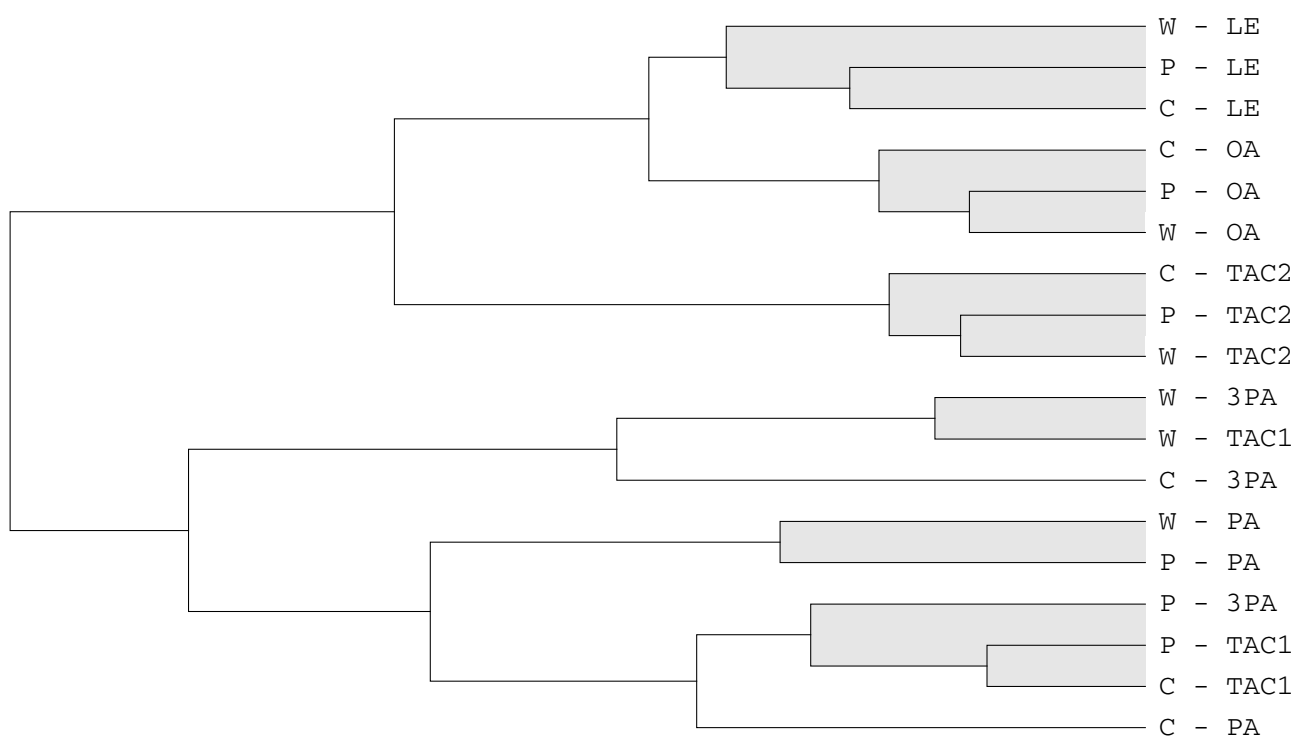

FIGURE 4. Dendrogram of the data sets presented in Table 5, applying the Canberra distance algorithms. Shaded area indicates level 8 and above.

similarly close relationship where the exploitation rates are low (PA, 3PA and TAC1). The main conclusion is, however, that clustering applies to management regimes rather than environmental scenarios. Apart from the two indicators where all cluster (age composition and profit), only one case is found where environmental scenarios cluster, namely for the warmer scenario in case of the average biomass indicator.

Figure 4 shows a dendrogram of the data in Table 5, applying the Canberra difference proposed by Faith et al. [1987]. In Figure 4 all indicator values are put together in a cluster analysis, different from the one presented in Table 6 where each indicator was treated independently. The cluster dendrogram (or cluster tree) presents the hierarchical clustering of the performed simulations based on the set of indicator values of each simulation. Horizontal lines extend left of each simulation and are connected to other horizontal lines when sufficient similarities are found. If this connection occurs to the right of other connections it indicates a closer relationship. If connection occurs far to the left, the horizontal lines (or the simulations represented by those) are more separated from each other. Figure 4 shows a convincing relationship between management regimes across the environmental 
TABLE 6. Indicator clustering. "C" represents cold scenario, "W" warm scenario and " 0 " the zero scenario (current situation). The management codes are from Table 3. A full clustering (of all environmental scenarios) of management regimes are indicated by bold fonts. Similarly full clusters of environmental regimes are indicated by bold symbols in parentheses. In two cases (indicators Age composition and Present value of flow of profit) all management regimes and environmental scenarios are clustered.

\begin{tabular}{|c|c|c|c|c|c|}
\hline Indicators & Clusters & & & & \\
\hline $\begin{array}{l}\text { Average } \\
\text { biomass }\end{array}$ & $\begin{array}{l}\operatorname{LE}(\mathrm{C}) \\
\operatorname{PA}(\mathrm{C}, 0) \\
3 \mathrm{PA}(\mathrm{C}, 0) \\
\operatorname{TAC} 1(\mathrm{C})\end{array}$ & $\begin{array}{l}\text { OA+TAC2+(W) } \\
\mathrm{LE}(0, \mathrm{~W}) \\
\mathrm{PA}(\mathrm{W}) \\
3 \mathrm{PA}(\mathrm{W}) \\
\mathrm{TAC} 1(0, \mathrm{~W}) \\
\end{array}$ & & & \\
\hline $\begin{array}{l}\text { Critical low } \\
\text { spawning } \\
\text { biomass } \\
\end{array}$ & $\begin{array}{l}\mathrm{PA}(\mathrm{C}, 0) \\
\mathrm{TAC} 1(\mathrm{C}) \\
3 \mathrm{PA}(0) \\
\end{array}$ & $\begin{array}{l}\text { OA+TAC2+LE } \\
\mathrm{TAC} 1(0, \mathrm{~W}) \\
\end{array}$ & $\begin{array}{l}\mathrm{PA}(\mathrm{W}) \\
3 \mathrm{PA}(\mathrm{C}, \mathrm{W})\end{array}$ & & \\
\hline $\begin{array}{l}\text { Catch } \\
\text { variance }\end{array}$ & TAC1 & $\begin{array}{l}\mathrm{PA}(\mathrm{C}, 0) \\
3 \mathrm{PA}(\mathrm{C}, 0)\end{array}$ & $\begin{array}{l}\mathbf{L E} \\
\mathrm{TAC2}(0) \\
\end{array}$ & $\begin{array}{l}\text { TAC2 }(\mathrm{C}, \mathrm{W}) \\
\mathrm{PA}(\mathrm{W}) \\
3 \mathrm{PA}(\mathrm{W}) \\
\end{array}$ & OA \\
\hline $\begin{array}{l}\text { Age } \\
\text { composition }\end{array}$ & $\begin{array}{l}\text { All } \\
\text { clustered }\end{array}$ & & & & \\
\hline $\begin{array}{l}\text { Distribution } \\
\text { in time }\end{array}$ & $\begin{array}{l}\mathbf{P A} \\
\mathrm{TAC} 1(\mathrm{C}) \\
\end{array}$ & $\begin{array}{l}\mathbf{L E}+\mathbf{3 P A} \\
\mathrm{TAC} 1(0, \mathrm{~W}) \\
\mathrm{OA}(\mathrm{W}) \\
\end{array}$ & $\begin{array}{l}\text { TAC2 } \\
\mathrm{OA}(\mathrm{C}, 0)\end{array}$ & & \\
\hline Profit & $\begin{array}{l}\text { TAC1 } \\
\text { LE }(\mathrm{W}) \\
\mathrm{PA}(\mathrm{C}) \\
3 \mathrm{PA}(\mathrm{C}, 0) \\
\end{array}$ & $\begin{array}{l}\text { OA + TAC2 } \\
\mathrm{LE}(\mathrm{C}, 0) \\
\mathrm{PA}(0)\end{array}$ & $\begin{array}{l}\mathrm{PA}(\mathrm{W}) \\
3 \mathrm{PA}(\mathrm{W})\end{array}$ & & \\
\hline $\begin{array}{l}\text { Present value } \\
\text { of flow } \\
\text { of profit }\end{array}$ & $\begin{array}{l}\text { All } \\
\text { clustered }\end{array}$ & & & & \\
\hline Employment & $\mathrm{PA}+3 \mathrm{PA}+\mathrm{TAC} 1$ & LE & $\begin{array}{l}\text { OA } \\
\text { TAC2 } \\
\end{array}$ & & \\
\hline
\end{tabular}

conditions, in particular, in the cases of high exploitations rates (the upper part of the figure). In fact this part of the figure constitutes one of the two main clusters of the whole data set.

9. Conclusions. The conclusions from the earlier study by Eide and Heen [2002] seem to be confirmed by the results presented above; namely, that choice of management regime seems to have a greater 
impact on the development of the Barents Sea fisheries than possible environmental changes caused by global warming (under the basic assumptions presented earlier). The dendrogram presented (Figure 4) shows strong clusters of management regimes and weaker clustering of environmental scenarios. The strong clustering of management regime across the environmental conditions are rather convincing in cases of high exploitation rates (TAC2, LE and OA). A weaker clustering is seen at the colder scenario in the case of PA and 3PA (precautionary approach without and with the 3 year rule), but this is the only sign of an environmentally caused clustering. The simulation results therefore strongly confirm previous results presented by Eide and Heen [2002], finding the management impact to be much greater than the impact from changing environmental conditions.

Other results from this study are however more unexpected and surprising. This refers both to the unexpected decline in profitability in the warmer scenario compared with zero and colder scenario, and the surprisingly high profitability of open access regimes.

The latter is obviously strongly linked to the increasingly fluctuating growth pattern seen in Figures 1-3 and the chosen entry/exit rates of the different fleets. The entry/exit dynamics allow the vessel groups to change gears and fishery but open also for a net increase/decrease in the total fleet. Changes in the entry/exit rates do not however seem to change the results dramatically. The fluctuations seem to be driven by changes in the age composition of the cod stock where the cannibalistic behavior of the cod stock has a substantial impact, together with other factors discussed elsewhere in this article. The fluctuating age composition causes occasionally extremely rich year classes which produce enormous profits. Periods before and after such events cause losses and negative profits. In sum the gains exceed the losses to the extent that open access provides the fleet with profits $30-40 \%$ above the profits of the reference regime (Table 5), also when considering a present value calculation. It should also be noted that the open access simulations only show fluctuating patterns, not downward sloping trends over time with respect to stock biomass, catches and profits. The more stable situations obtained by lower exploitation rates do not provide the fleet with stock levels close to the peaks seen in the high exploitation cases, and the extreme annual profits related to this 
high stock abundance are not found. Similarly the high losses and risks related to extremely low stock levels are also avoided.

The reduced profitability caused by a warmer environmental situation compared with a colder one may depend on the current implementation of primary and secondary production and the corresponding suitability of the fish species. These results therefore may change when implementing a more sophisticated and area distributed primary and secondary production model. Also here, however, the age composition of the cod stock seems to play a crucial role. As a warmer climate causes an increased individual growth and maturation is linked to fish length, maturation age is lowered. The cannibalistic dynamics are also changed by this and the age fluctuations in stock seem to be less pronounced. This may give rise to a less productive situation over time. Finally the selection pattern in the different gears combined with changes in age composition, growth pattern (including recruitment), and fleet dynamics, may potentially give rise to the slightly surprising results regarding profitabilities of different environmental scenarios. The complexity often referred to in this article do not allow for a simple conclusion on this matter, and the simulation results need to be studied more thoroughly before any certain conclusions can be reached.

Finally, it is useful to keep in mind that the conclusions in this article are based on a very crucial assumption of no significant shift in ecosystem structure in the cases of environmental changes. Possible effects as introduction of new species replacing some of the current main species may cause significant changes not considered in this article.

Acknowledgments. The development of the EconMult model and the global warming impact analyses is part of the EU-funded project BALANCE EVK2-2002-00169. The BALANCE project has involved a multidisciplinary collaboration which has made it possible to parameterise a fully integrated modeling tool dealing with the management of the Barents Sea fish resources. The contribution from the BALANCE community and work packages leader Knut Heen is greatly appreciated. The author would also like to thank Ola Flaaten, Rögnvaldur Hannesson and one anonymous referee for helpful and constructive comments on earlier drafts. 


\section{ENDNOTES}

1. For technical details regarding the implementation of cost and price information from Anon. [2000] into EconSimp2000, please contact the author.

\section{REFERENCES}

Anon. [2000], Lønnsomhetsundersøkelser for Helårsdrevne Fiskefartøy 8 Meter Største Lengde Og Over, The Norwegian Fisheries Directorate, Bergen, Norway (in Norwegian).

Bjarte Bogstad, Kjellrun Hiis Hauge and Øystein Ulltang [1997], MULTSPEC-A Multi-Species Model for Fish and Marine Mammals in the Barents Sea, J. Northwest Atl. Fish. Sci. 22, 317-341.

M. Åsnes [2005], Prost Users Guide, Internal note, Norwegian Institute of Marine Research (IMR), Bergen, Norway.

Arne Eide and Ola Flaaten [1998], Bioeconomic Multispecies Models of the Barents Sea Fisheries, in Models for Multispecies Management (Tor Rødseth, ed.), Physica-Verlag, Heidelberg, New York, pp. 141-172.

Arne Eide and Knut Heen [2002], Economic Impacts of Global Warming. A Study of the Fishing Industry in North Norway, Fish. Research 56, 261-274.

Arne Eide, Frode Skjold, Frank Olsen and Ola Flaaten [2003], Harvest Functions: The Norwegian Bottom Trawl Cod Fisheries, Mar. Resource Econ. 18, 81-93.

D.P. Faith, P.R. Minchin and L. Belbin [1987], Compositional Dissimilarity as a Robust Measure of Ecological Distance, Plant Ecol. (Historical Archive) 69, 57-68.

Johannes Hamre [1994], Biodiversity and Exploitation of the Main Fish Stocks in the Norwegian-Barents Sea Ecosystem, Biodiversity Conserv. 3, 473-492.

John Houghton [2005], Global Warming, Rep. Prog. Phys. 68, 1343-1403.

Geir Huse, Steve Railsback and Anders Fernø [2002], Modelling Changes in Migration Pattern of Herring: Collective Behaviour and Numerical Domination, J. Fish Bio. 60, 571-582.

D. Jacob, U. Andrae, G. Elgered, C. Fortelius, L.P. Graham, S.D. Jackson, U. Karstens, Chr. Koepken, R. Lindau, R. Podzun, B. Rockel, F. Rubel, H.B. Sass, R.N.D. Smith, B.J.J.M. Van den Hurk and X. Yang [2001], A Comprehensive Model Intercomparison Study Investigating the Water Budget during the BALTEXPIDCAP Period, Meteorol. Atmos. Phys. 77, 19-43.

Reto Knutti and Thomas F. Stocker [2002], Limited Predictability of the Future Thermohaline Circulation Close to an Instability Threshold, J. Climate 15, 179-186.

Manfred Lange [2003], The Barents Sea Impact Study (BASIS): Methodology and First Results, Continental Shelf Research 23, 1673-1694.

Frank L. Lewis and Kai Liu [1996], Towards a Paradigm for Fuzzy Logic Control, Automatica 32, 167-181.

Geir Ottersen, Bjørn Ådlandsvik and Harald Loeng [2000], Predicting the Temperature of the Barents Sea, Fish. Oceanogr. 9, 121-135. 
Ole P. Pedersen, Dag Slagstad and Kurt Tande [2003], Hydrodynamic Model Forecasts as a Guide for Process Studies on Plankton and Larval Fish, Fish. Oceanogr. 12, 369-380.

Stefan Rahmstorf [1997], Risk of Sea-Change in the Atlantic, Nature 388, $825-826$.

Sigurd Tjelmeland and Bjarte Bogstad [1998a], Biological Modelling, in Models for Multispecies Management (Tor Rødseth, ed.), Physica-Verlag, Heidelberg, New York, pp. 69-92.

Sigurd Tjelmeland and Bjarte Bogstad [1998b], MULTSPEC-A Review of a Multispecies Modelling Project for the Barents Sea, Fish. Research 37, 127-142.

Reidar Toresen and Ole Johan Østvedt [2000], Variation in Abundance of Norwegian Spring-Spawning Herring (Clupea harengus, Clupeidae) throughout the 20th Century and the Influence of Climatic Fluctuations, Fish Fisher. 1, 231-256.

Michael Vellinga and Richard A. Wood [2002], Global Climatic Impacts of a Collapse of the Atlantic Thermohaline Circulation, Climatic Change 54, 251-267.

Arild Wikan and Arne Eide [2004], An Analysis of a Nonlinear Stage-Structured Cannibalism Model with Application on the Northeast Arctic Cod Stock, Bull. Math. Biol. 66, 1685-1704. 
